http://jmscr.igmpublication.org/home/ ISSN (e)-2347-176x ISSN (p) 2455-0450 crossref DOI: https://dx.doi.org/10.18535/jmscr/v8i10.07

\title{
Surgical Release of the First Extensor Compartment for de Quervain's Tenosynovitis
}

\author{
Authors \\ Prof. Bashir Ahmad Mir ${ }^{1}$, Dr Asif Sultan ${ }^{2}$, Dr Mudasir Nazir Bhat ${ }^{3}$ \\ Postgraduate Department of Orthopaedics, Government Medical College Srinagar J\&K, India
}

\begin{abstract}
Introduction: Repetitive and forceful manual work with wrist deviated to ulnar wards and thumb abducted and extended may lead to de Quervain's tenosynovitis. Both non surgical and surgical options are there for the treatment of this condition. However, surgical decompression is considered when conservatives measures failed after tried for 3-6 months.

Materials and Methods: A prospective study conducted in Government Medical College Srinager from September 2016 to Augest 2018. A total of 44 patients of de Quervain's tenosynovitis were included in the study.

Results: Almost all cases cured as there was insignificant pain or tenderness, VAS score was below 3 and negative Finkelstein test was seen in all patients. Preoperative VAS score was reduced from $9.2 \pm 1.32$ to $1.52 \pm 2.38$ at 1 month, $1.41 \pm 2.52$ at 6 months, and $1.02 \pm 2.69$ at 12 -month follow-up. Preoperative Quick DASH score was $84.39 \pm 18.29$ which was reduced to $20.89 \pm 20.74$ at 1 month, $16.32 \pm 22.82$ at 6 months and $14.92 \pm 24.25$ at 12-month follow-up and it was found stastically significant ( $p$ value $<0.005$ ). Three patients developed an infection and were cured with an antibiotic. Two patients had tendon subluxation after the operation that were treated subsequently.

Conclusion: Most of the patients were completely relieved from de Quervain's tenosynovitis with surgical intervention.
\end{abstract}

Keywords: De Quervain's tenosynovitis, open surgery.

\section{Introduction}

De Quervain's disease is defined as a stenosing tenosynovitis of the abductor pollicislongus (APL) and the extensor pollicisbrevis (EPB) within the first extensor compartment of the wrist, formed by the radius and dorsal carpal ligaments ${ }^{(1-3)}$ rather than inflammation ${ }^{(4)}$ It was described by a Swiss physician Fritz de Quervain in $1895^{(5,6)}$. It causes radial wrist pain that increases with activity ${ }^{(7)}$. Patient with de Quervain's disease presents with pain over the radial styloid process which may radiate to thumb, forearm, or shoulder. On physical examination swelling, tenderness and crepitation may be found. Pain on thumb abducted with clench fist and wrist ulnar deviation (Finkelstein test) suggests de Quervain's tenosynovitis ${ }^{(13)}$. Steroid injection into the tendon sheath is a standard method as a primary treatment in uncomplicated cases ${ }^{(8)}$. Although steroid injection is common, complications such as subcutaneous atrophy, fat necrosis, weakening or rupture of tendons, and depigmentation have been reported after this treatment regimen ${ }^{(9-12)}$. However, surgical decompression is considered when conservatives lines of treatment has failed after about a period of 3-6 months ${ }^{(14)}$. Presence of 
aberrant tendon within a separate compartment and other diseases like intersection syndrome, arthritis, proximal nerve compression syndrome may cause surgical failure ${ }^{(15)}$

\section{Material and Method}

This study was conducted on 44 patients during a period of 2 years between sept 2016 to Aug 2018. All patients with clinical signs and symptoms of de Quervain's disease (positive Finkelstein tests, localized tenderness over the first dorsal compartment, and positive sign on active EPB extension test), Conservative treatment with or without corticosteroid injection tried for 3-6 months were included in the study. Patients below 20 years of age, Presence of pregnancy and other diseases like RA, gout, DM, infection or skin disease were excluded from the study. Ethical clearance and written informed consent was taken from each patient. All the 44 patients were followed-up reguraly after 1 month, 6 months and 12 months. Assessment of any pain and tenderness over the radial styloid process and results of Finkelstein's test were recorded at every follow up. Visual Analogue Scale (VAS) score for pain and DASH score for functional outcome were used for the study.

\section{Surgical Technique}

The skin was infiltrated with $2 \%$ lidocaine $\mathrm{HCl}$ and then painting and draping were done. Tourniquet was then applied. An oblique incision over the extensor brevis tendon was given. Radial sensory nerve branches were identified and procteted. The EPB tendon was exposed and identified just distal to the first extensor compartment. After lifting the EPB tendon, the extensor retinaculum covering the EPB was incised longitudinally along the EPB tendon on its dorsal side. With the thumb, adducted and wrist flexed the two tendons (EPB and APL) were lifted from the groove. The tendons were released and the presence of any aberrant tendon and separate compartment were searched. Skin was closed and wound was dressed.

\section{Results}

44 patients with de Quervain's tenosynovitis were taken for surgical treatment. Mean age was 42.25 \pm 8.14 years whereas age range was $28-58$ years. Thirty four $(77.27 \%)$ patients were female and the rest $10(22.72 \%)$ were male.

Most of the patients were, housewife $48 \%$, hard workers $35.5 \%$ and others were $16.5 \%$. The right hand was affected in $82.4 \%$ cases and left in $17.6 \%$ cases. Four $(9.09 \%)$ patients had not improved after 12 months of follow-up. Rest 40 $(91.01 \%)$ cases were cured as there was significant improvement in pain or tenderness, VAS score was below 3 and Finkelstein test was negative. Preoperative VAS score was significantly reduced from $9.2 \pm 1.32$ to $1.52 \pm$ 2.38 at 1 month, $1.41 \pm 2.52$ at 6 months and 1.02 \pm 2.69 at 12-month follow-up. Functional outcomes measured using Quick DASH were also reduced significantly. Preoperative Quick DASH score was $84.39 \pm 18.29$ which was reduced to $20.89 \pm 20.74$ at 1 month, $16.32 \pm 22.82$ at 6 months and $14.92 \pm 24.25$ at 12-month follow-up.

\begin{tabular}{|l|c|c|c|}
\hline & & $\begin{array}{c}\text { VAS } \\
\text { SCORE }\end{array}$ & $\begin{array}{c}\text { DASH } \\
\text { SCORE }\end{array}$ \\
\hline \multirow{2}{*}{ Pre-operative } & Mean & 9.2 & 84.39 \\
\cline { 2 - 4 } & SD & 1.32 & 18.29 \\
\hline \multirow{2}{*}{ At 1 Month } & Mean & 1.52 & 20.89 \\
\cline { 2 - 4 } & SD & 2.38 & 20.74 \\
\hline \multirow{2}{*}{ At 6 Months } & Mean & 1.41 & 16.32 \\
\cline { 2 - 4 } & SD & 2.52 & 22.82 \\
\hline \multirow{2}{*}{ At 12 Months } & Mean & 1.02 & 14.92 \\
\cline { 2 - 4 } & SD & 2.69 & 24.25 \\
\hline
\end{tabular}

\section{Discussion}

We achieved excellent clinical outcome in terms of pain relief with minimal complication using release of the first extensor compartment for the treatment of deQuervain's disease. There was no subluxation of the tendon after the index surgery. Few patients develop infection, that was subsequently treated by antibiotics.

Regarding the functional outcome, the DASH developed by "Upper Extremity Collaborative Group" is considered as a reliable outcome measure in pathology of upper extremities and is widely accepted. Regarding pain relief, this 
procedure was found effective in relieving both overall and night pain. In our study EPB tendon sheath was separated from the APL in large number of the patients. In 9 patients ganglia over the first extensor compartment was found to cause trouble .Even though we cannot know the causeand-effect relationship between the ganglia and de Quervain's disease, we can speculate the association between the ganglion and de Quervain's disease by the incidence of ganglion. After resection of these ganglia, the symptoms disappeared and there was no recurrence case at the final clinical follow-up. In summary, ganglia over the first extensor compartment and the separate septum of EPB are often related

to de Quervain's disease. Dorsal release of first extensor compartment for refractory de Quervain's disease resulted in good clinical outcome with minimal morbidity.

\section{Conclusion}

The surgical release of first dorsal compartment for de Quervain's disease was found safe, easy and effective with minimal complications.

\section{References}

1. Clarke MT, Lyall HA, Grant JW, Matthewson MH. The histopathology of de Quervain's disease. J Hand Surg Br. 1998; 23(6):732-4.

2. de Quervain F. On a form of chronic tendovaginitis. (Translated article: CorB1.f.schweiz. Aerzrte 1895:25:389-94). J Hand Surg Br. 2005;30(4):388-91.

3. Kay NR. De Quervain's disease. Changing pathology or changing perception? J Hand Surg Br. 2000;25(1):65-9.

4. Green DP, Hotchkiss RN, Pederson WC, Wolfe SW, eds. Green's operative hand surgery. 5th ed. New York: Elsevier, Churchill-Livingstone; 2005.

5. deQuervain F. On a form of chronic tendovaginitis. J Hand Surg Br. 30: 388-391 (2005).
6. deQuervain F. On the nature and treatment of stenosing tendovaginitis on the styloid process of the radius. J Hand Surg Br. 30: 392-394 (2005).

7. Stein AH, Ramsey RH, Key Ja. Stenosingtendovaginitis at the radial styloid process (De Quervain's disease). AMA Arch Surg. 1951;63:216-28.

8. Oh JK, Messing S, Hyrien O, Hammert WC. Effectiveness of Corticosteroid Injections for Treatment of de Quervain's Tenosynovitis. Hand (NY). 2017;12:357-61

9. Lee ZH, Stranix JT, Anzai L, Sharma S. Surgical anatomy of the first extensor compartment: A systematic review and comparison of normal cadavers vs. De Quervain syndrome patients. J Plast Reconstr Aesthet Surg. 2017;70:127-31.

10. Finkelstein H. Stenosing tendovaginitis at the radial styloid process. J Bone Jt Surg. 1930;12:509-40.

11. Kutsumi K, Amadio PC, Zhao C, Zobitz ME, Tanaka T, An KN. Finkelstein's test: a biomechanical analysis. J Hand Surg Am. 2005;30:130-5.

12. Alexander RD, Catalano LW, Barron OA, Glickel SZ. The extensor pollicisbrevis entrapment test in the treatment of de Quervain's disease. J Hand Surg Am. 2002;27:813-6.

13. Ilyas A. Nonsurgical treatment for de Quervain's tenosynovitis. J Hand Surg. 34: 928-929 (2009)

14. .Witt J, Pess G, Gelberman R. Treatment of de Quervain tenosynovitis. A prospective study of the results of injection of steroids and immobilization in a splint. J Bone Joint Surg. 73: 219- 222 (1991).

15. Altay M, Erturk C, Isikan U. De Quervain's disease treatment using partial resection of the extensor retinaculum: A short-term results survey. Orthop Traumatol Surg Res. 97: 489493 (2011). 